\title{
Ação educativa em saúde desenvolvida com trabalhadoras de materiais recicláveis
}

\author{
Education action in health developed with recyclable material workers \\ Acción educativa en salud desarrollada con trabajadores de materiales reciclables
}

Recebido: 05/05/2021 | Revisado: 10/05/2021 | Aceito: 17/05/2021 | Publicado: 04/06/2021

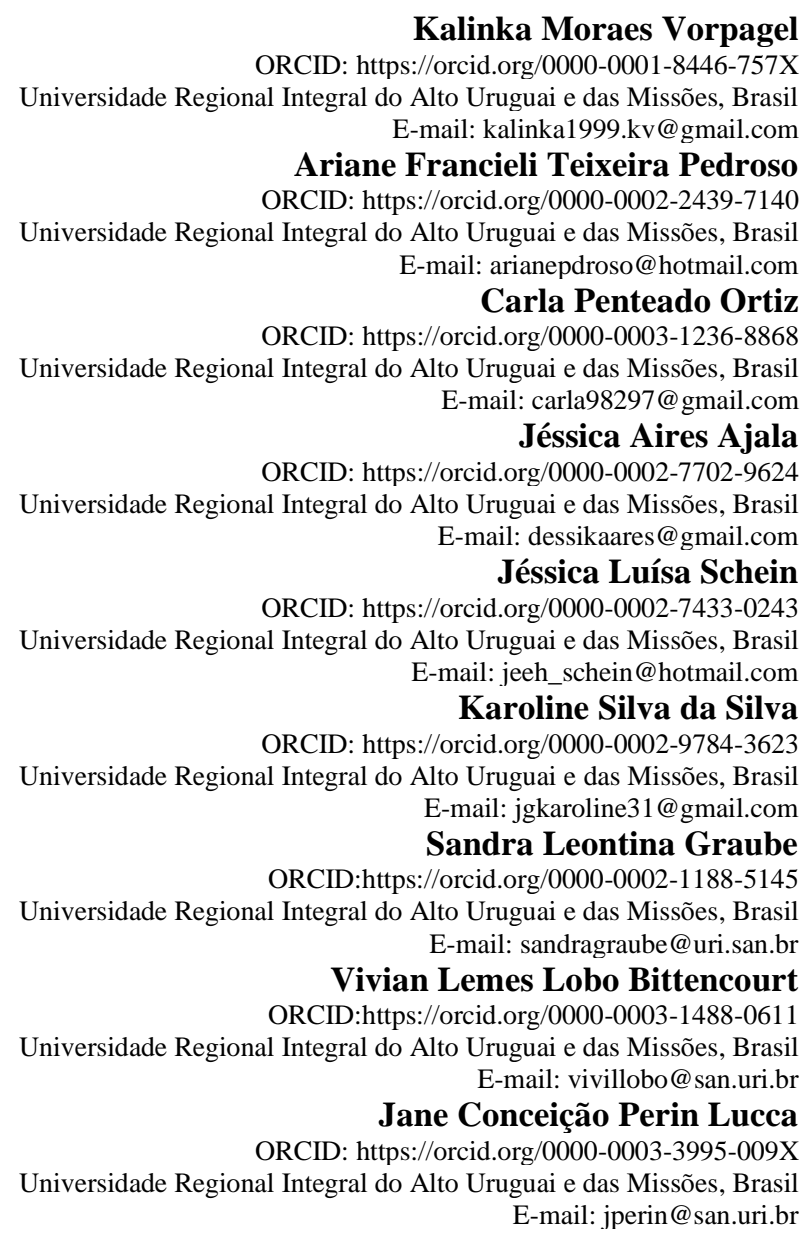

\section{Resumo}

As mulheres catadoras exercem papel significativo no ciclo da reciclagem de materiais, e através do seu trabalho promovem a sustentabilidade do planeta, na tentativa de diminuir resíduos sólidos. Devido a essa situação, ficam expostas a riscos ocupacionais que influenciam diretamente em sua saúde e sexualidade. O objetivo do estudo é relatar uma ação educativa em saúde desenvolvida com trabalhadoras de materiais recicláveis sobre transformações corporais nas fases da vida de mulheres. Trata-se de um relato de experiência, de abordagem qualitativa, descritiva, aplicada e desenvolvida em uma cooperativa de reciclagem da região Noroeste do estado do Rio Grande do Sul, com sete trabalhadoras de material reciclável, com idades entre 18 e 40 anos. Percebeu-se que estas mulheres apresentam poucos conhecimentos sobre o próprio corpo, relataram dúvidas quanto à utilização dos métodos contraceptivos e sobre o funcionamento do sistema reprodutor feminino, mas demonstram autoestima e aceitação em relação à sua imagem corporal. As ações educativas desenvolvidas pela enfermagem, com esta classe de trabalhadores, auxiliam no despertar de um olhar mais abrangente da sociedade e das diversas classes sociais, em uma atuação profissional que busca um cuidado humanizado e igualitário.

Palavras-chave: Catadores; Sexualidade; Mulheres; Enfermagem; Educação em saúde.

\footnotetext{
Abstract

Women waste pickers play a significant role in the recycling cycle of materials and, through their work, promote the sustainability of the planet in an attempt to reduce solid waste. Due to this situation they are exposed to occupational risks that directly influence their health and sexuality. The objective of the study is to report an educational health action
} 
developed with recyclable material workers on bodily transformations in the phases of women's lives. It is an experience report, with a qualitative, descriptive, applied approach, developed in a recycling cooperative in the Northwest region in the state of Rio Grande do Sul, with seven recyclable material workers, aged between 18 and 40 years. It was noticed that these women have little knowledge about their own body, reported doubts about the use of contraceptive methods and about the functioning of the female reproductive system, but demonstrate self-esteem and acceptance of their body image. The educational actions developed by nursing, with this class of workers, help to awaken a more comprehensive view of society and different social classes, in a professional performance that seeks humanized and egalitarian care.

Keywords: Waste pickers; Sexuality; Women; Nursing; Health education.

\section{Resumen}

Las mujeres recicladoras juegan un papel importante en el ciclo de reciclaje de materiales y, a través de su trabajo, promueven la sustentabilidad del planeta en un intento por reducir los residuos sólidos. Por esta situación están expuestas a riesgos laborales que inciden directamente en su salud y sexualidad. El objetivo del estudio es dar a conocer una acción educativa en salud desarrollada con trabajadoras de materiales reciclables sobre las transformaciones corporales en las fases de la vida de las mujeres. Se trata de un relato de experiencia, con enfoque cualitativo, descriptivo, aplicado, desarrollado en una cooperativa de reciclaje en la región Noroeste en el estado de Rio Grande do Sul, con siete trabajadores de materiales reciclables, con edades entre 18 y 40 años. Se notó que estas mujeres tienen poco conocimiento sobre su propio cuerpo, reportaron dudas sobre el uso de métodos anticonceptivos y sobre el funcionamiento del aparato reproductor femenino, pero demuestran autoestima y aceptación de su imagen corporal. Las acciones educativas que desarrolla la enfermería, con esta clase de trabajadores, ayudan a despertar una mirada más integral a la sociedad y las diferentes clases sociales, en una actuación profesional que busca un cuidado humanizado e igualitario.

Palabras clave: Recicladores; Sexualidad; Mujer; Enfermería; Educación para la salud.

\section{Introdução}

Em níveis mundiais, a desigualdade de gênero, relacionada às questões trabalhistas, é algo comum. Essa desigualdade vem se arrastando através dos séculos, contribuindo, ainda mais, na precariedade do trabalho feminino, no qual a mulher, mesmo com sua emancipação do ambiente doméstico e interagindo com a realidade social, se encontra em posição de desigualdade, vulnerabilidade, passando despercebidas por aspectos sociais e econômicos, vivendo em condições precárias, estando sujeitas a impactos na saúde (Coelho et al., 2018).

Neste contexto, encontramos as mulheres catadoras, que exercem um papel significativo no ciclo da reciclagem de materiais, promovendo, através de seu trabalho, a sustentabilidade do planeta, na tentativa de diminuir resíduos sólidos e contribuir para a redução exacerbada da extração da matéria-prima da natureza, através da recuperação destes insumos, sujeitas a uma longa carga horária de atividades e a fatores de riscos ocupacionais (Nascimento; Cabral, 2019).

Devido a essa situação, o corpo da trabalhadora passa cotidianamente por situações que a expõe a agentes nocivos à saúde, passando por transformações que se manifestam de formas distintas, nas diversas fases da vida, de tal forma que o trabalho, no contexto das catadoras, acaba influenciando diretamente na sexualidade, promoção da emancipação e autonomia, comprometendo física, psíquica e emocionalmente sua trajetória de vida.

Na conjuntura do trabalho, o preconceito com mulheres, assim como com pessoas negras, é presente, o que acarreta maior dificuldade na inserção no mercado de trabalho, assim como na remuneração (Proni et al., 2015). Estudo realizado por Coelho et al. (2016, p. 7) constatou que "a feminização do trabalho veio acompanhada pelo subemprego da mulher no mercado de trabalho", o que reforça a desigualdade, a vulnerabilidade e a precariedade que se expõe, experienciando diversos riscos e danos no corpo e em sua saúde, o que sinaliza a necessidade de ações em saúde por profissionais habilitados.

A discriminação ainda está presente, ocorrendo vagas apenas para o sexo masculino, e outras restrições, como questões de idade e cor, e os grupos mais vulneráveis acabam oscilando no ciclo econômico, através de empregos informais e trabalho braçal. Para Proni et al. (2015), apesar das diversas ações e penalidades legais impostas aos vários tipos de discriminação, o tratamento desigual continua, uma vez que se disseminaram formas de encobrir a discriminação na sociedade brasileira. Nesse sentido, no que se refere à renda, observa-se acentuada superioridade entre os homens em comparação com mulheres, uma vez 
que há maior participação masculina no emprego com vínculo formal, enquanto as mulheres ocupam a maior proporção no trabalho doméstico informal (Proni et al., 2015).

A dificuldade em conseguir uma ocupação formal, e a exclusão do mercado de trabalho, causando a diminuição nas rendas de suas famílias, faz com que mulheres busquem se inserir na ocupação de recicladoras para obter renda, prover sustento do seu lar e participar do mundo do trabalho (Nascimento; Cabral, 2017). A coleta seletiva e a reciclagem expressam uma maneira de reduzir os problemas de lixo urbano e gerar emprego para cidadãos que necessitam obter uma renda e não tem trabalho formal.

A contar do momento em que a mulher se insere no mercado de trabalho, seja ele formal ou informal, a sua jornada acaba sendo duplicada, passando a acumular o trabalho doméstico e o trabalho profissional, posto que a sociedade ainda vê o trabalho doméstico como incumbência feminina. A partir disso, vemos que há um cenário de desigualdade, em que há funções para homens e funções para mulheres (Moura; Sopko, 2018).

A vulnerabilidade tem sua percepção diretamente ligada a questões do ambiente, associadas a situações de pobreza e privação global. Mediante essas circunstâncias, se torna relevante um cuidado voltado a questões sociais, e um olhar especial relacionado ao espaço territorial, facilitando uma atenção mais específica, e fortalecendo o modelo de equidade (Rodrigues et al., 2020).

As ações educativas em saúde estão inseridas na atuação do enfermeiro, sendo um instrumento para estabelecer vínculo com cada usuário, família e comunidade. As ações podem incluir diálogo, de modo a facilitar a compreensão, buscando novos hábitos e atitudes, devendo sempre considerar e valorizar as experiências dos usuários. A educação e promoção da saúde são meios de conscientização acerca do autoconhecimento e autocuidado, gerando significativas transformações no cotidiano das catadoras, e estimulando a autoestima, com consequente melhoria da qualidade de vida, aprimorando a relação com os outros e consigo mesmas (Costa et al., 2020).

Devido à situação de vulnerabilidade social em que se encontram essas mulheres, geralmente marginalizadas pela atividade que exercem, reciclando materiais que muitas vezes são descartados como lixo, sendo vistas na sociedade de forma discriminada, na qual a sua autoestima fica comprometida, realizou-se, com esses fatores servindo como estímulo, a ação educativa descrita neste texto, com vistas a contribuir para a vida profissional e pessoal dessas trabalhadoras, para uma melhor valorização de si e de seu papel relevante na sociedade. A enfermagem exerce um papel de agente de transformações, proporciona conhecimento, com ações de educação em saúde, por isso o enfermeiro precisa de um olhar voltado a diversas classes sociais. O objetivo deste texto é relatar uma ação educativa em saúde desenvolvida com trabalhadoras de materiais recicláveis sobre transformações corporais nas fases da vida de mulheres.

\section{Metodologia}

Trata-se de um relato de experiência, de abordagem qualitativa, descritiva, aplicado. A ação educativa em saúde descrita neste artigo foi desenvolvida em uma cooperativa de reciclagem, da região Noroeste do estado do Rio Grande do Sul, por seis alunas do oitavo semestre do curso de graduação em Enfermagem de uma universidade comunitária, localizada na mesma região da cooperativa de reciclagem. O planejamento e execução da ação educativa foi acompanhado por uma docente vinculada à disciplina curricular "Projeto de intervenção profissional". Na abordagem qualitativa os dados são obtidos através de entrevistas, discussões ou pela observação, não podendo ser quantificada, com uma definição mais ampla (Gil, 2008; Ludke et al., 2013). Para Thiollent, (2009), a pesquisa aplicada, se caracteriza em meio a atividades de organizações, grupos e instituições, no qual busca o diagnóstico identificação de questões e soluções de problemas encontrados, através de objetivos específicos. Relato de experiência, retrata uma reflexão sobre um conjunto de ações que tratam de uma situação vivenciada na esfera profissional e que é de relevância para a comunidade científica (Cavalcante, 2012). 
O estudo sucedeu-se com sete trabalhadoras de material reciclável dessa cooperativa, com idades entre 18 e 40 anos, tendo como critério de inclusão fazer parte da cooperativa de reciclagem, aceitar participar e estar presente no dia da ação educativa. Caso houvesse algum desconforto durante a atividade, ficou esclarecido que a participante poderia desistir a qualquer momento.

A ação educativa foi organizada em quatro etapas. A primeira atividade foi realizada de maneira motivadora, através de uma decoração, com frases de encorajamento e incentivo no sanitário feminino da cooperativa de reciclagem, com a finalidade de ajudar e encorajar essas mulheres na vida profissional e pessoal. As atividades seguintes ocorreram de forma lúdica, com a segunda etapa sendo desenvolvida por meio de uma dinâmica e teve como finalidade a percepção do corpo externo de cada participante e a maneira como elas se enxergam diante da sociedade. Foram distribuídos materiais, como papel pardo e canetas, para desenhar a imagem que tem do corpo externo, analisando a maneira como se observam.

Na terceira etapa, as acadêmicas de enfermagem, sob orientação da docente, realizaram exposição oral sobre o aparelho reprodutor feminino e métodos contraceptivos. Para essa atividade, foram levadas imagens dos órgãos internos do aparelho genital feminino, assim como modelos anatômicos do aparelho genital feminino interno e externo, do laboratório de enfermagem da universidade, para que as mulheres pudessem localizá-los e descrever sua função nas imagens que desenharam.

$\mathrm{Na}$ quarta etapa foi realizada uma roda de conversa, com o intuito de esclarecer as dúvidas e questionamentos dessas mulheres, em que as acadêmicas de enfermagem e a docente procuram desmistificar mitos e tabus que culturalmente essas mulheres traziam consigo. O encontro foi encerrado com o sorteio de um kit com produtos de cuidados pessoais, para agradecer a participação dessas trabalhadoras e incentivar o autocuidado.

\section{Resultados e Discussão}

No dia 17/11/2020, às $13 \mathrm{~h} 30 \mathrm{~min}$, por $1 \mathrm{~h} 30 \mathrm{~min}$, reuniram-se na sala de convivência da cooperativa de triagem de materiais recicláveis seis acadêmicas de enfermagem, a docente da disciplina e sete trabalhadoras da cooperativa de triagem de materiais recicláveis. Esse encontro ocorreu com a finalidade de proporcionar um momento de reflexão, discussão e informação sobre as diferentes fases e transformações que ocorrem no corpo da mulher, atualizando conhecimentos, desmistificando mitos e tabus que estão arraigados na experiência e na cultura dessas mulheres que se encontram em situação de vulnerabilidade social.

A atividade começou, na primeira etapa, com as acadêmicas de enfermagem realizando a decoração com frases e imagens coloridas em EVA, no sanitário feminino da cooperativa. Em um estudo realizado por Winters et al. (2018), as autoras relataram atividades de empoderamento com mulheres em vulnerabilidade social, e destacam que a enfermagem, por meio do diálogo e de estratégias diferenciadas, fomenta a assistência em saúde nos diferentes círculos sociais, o que auxilia para favorecer o empoderamento e a autonomia, principalmente em comunidades vulneráveis.

A segunda etapa teve início na sala de convivência da cooperativa, na qual as mulheres foram convidas e estimuladas a desenhar a imagem que seu corpo reflete (Figura 1). Para isso, foi fornecido papel pardo e pincel atômico. A princípio manifestaram dificuldade para realizar o desenho, mas como as acadêmicas de enfermagem também participaram da prática, logo se integraram e desenvolveram a atividade de forma descontraída e divertida. Destaca-se, nesse momento, que algumas de forma singela e sincera faziam referências ao desenho de si e também de suas colegas, tornando o ambiente descontraído e rico em trocas de informações, tanto para elas como para as acadêmicas. 
Figura 1 - Oficina de desenho corporal.
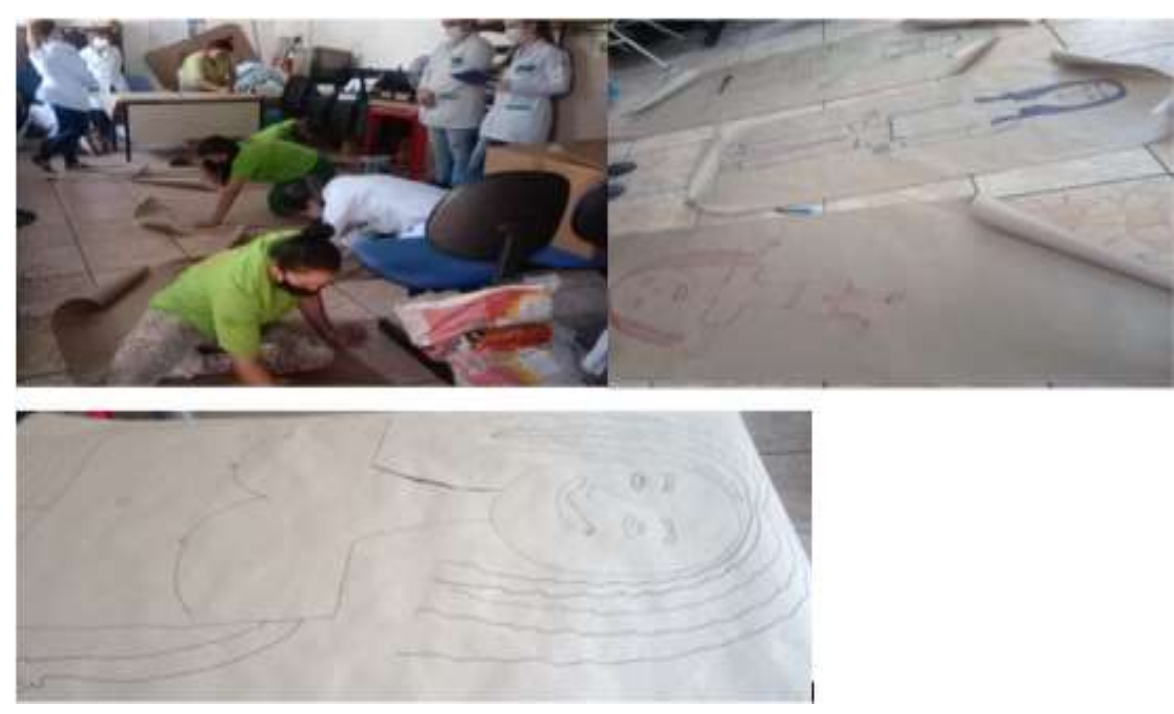

Fonte: Acervo pessoal das autoras.

Os desenhos revelaram que nesta fase da vida as mulheres estão mais atentas às partes do corpo que mais gostam, como o busto, os olhos, as sobrancelhas e os cabelos, deixando de lado os aspectos negativos em relação à imagem corporal. Através dos desenhos, foi possível destacar alguns pontos de como cada mulher se enxerga, como a altura, que foi altamente relevante e, em um dos desenhos, a participante se destacou em uma miniatura, relatando a sua baixa estatura. Uma das mulheres, que estava gestante, salientou em sua fala a forma mais volumosa de seu corpo e as mamas grandes e caídas, mas demonstrando sua autoaceitação, assim como os cabelos volumosos, mas escondendo a parte das pernas, por ser citada em alguns momentos como se tivesse pernas tortas.

As tendências atuais, provocadas principalmente pela mídia, estabelecem exigências e padrões estéticos de beleza, podendo estes prejudicar a evolução e equilíbrio do ser humano (Saur; Pasian; Loureiro, 2010). A imagem corporal e mental não são efeitos somente de elementos visuais, mas também da vivência pessoal, visto que o elo do indivíduo com a sociedade pode incitar na elaboração da autoimagem, influenciada pelos meios de comunicação, que instigam o que deve ser um corpo ideal, podendo provocar alterações e transtornos de imagem. Experiências associadas a observações negativas feitas por pessoas com quem se convive podem ser razões para distúrbios com a autoimagem (Loiloa, 2017).

Em seguida, na terceira etapa as acadêmicas de enfermagem questionaram o conhecimento prévio das mulheres sobre os órgãos do sistema reprodutor feminino, sua localização e a função destes órgãos no corpo humano. Para isso, foram utilizados os desenhos realizados pelas trabalhadoras anteriormente e imagens impressas (Figura 2), assim como peças anatômicas do aparelho reprodutor feminino. 
Figura 2 - Esclarecendo Dúvidas.

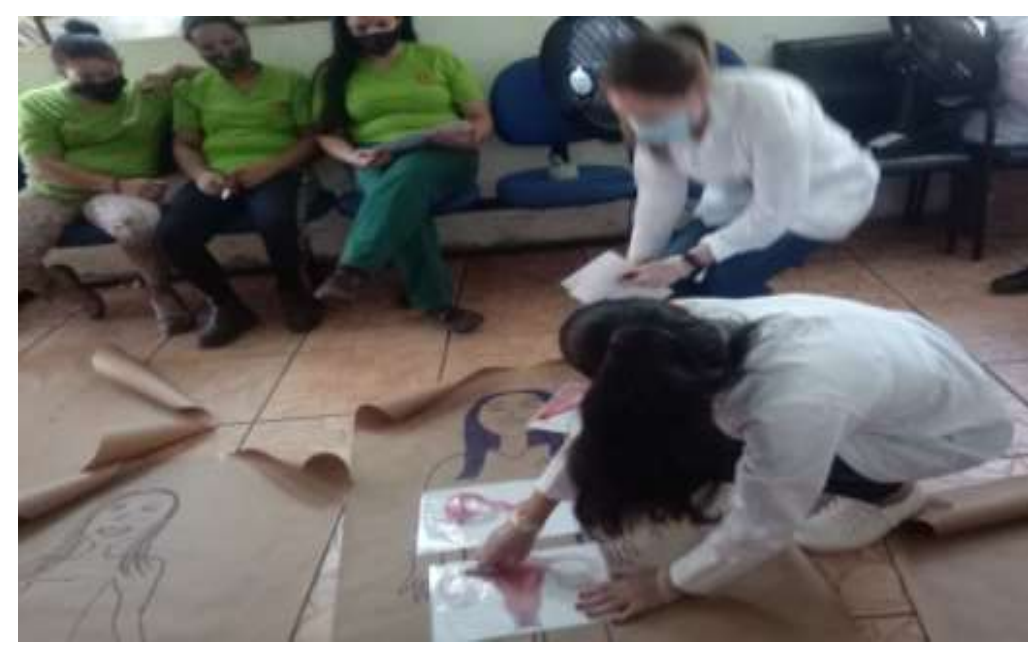

Fonte: Acervo pessoal das autoras.

Através dessas ferramentas, foram sendo explicadas as funções desses órgãos e os hormônios que atuam no sistema reprodutor feminino, desmistificando tabus, mitos e esclarecendo dúvidas, principalmente sobre como ocorre a ovulação e o período gestacional, pois havia duas mulheres gestantes. A atividade lúdica é uma alternativa baseada no entretenimento, a fim de estimular o aprendizado e a criatividade, relacionadas a jogos e brincadeiras, estimulando a participação (Silva et al., 2017). Metodologias dinâmicas e lúdicas favorecem para atingir objetivos esperados e tornar a aprendizagem significativa, por isso é necessário “dinamizar o processo educacional, articulando métodos” que auxiliem de forma inovadora a "construção e ampliação do conhecimento e das habilidades" (Lemos; Padilha, 2018, p. 13).

Foram abordados métodos contraceptivos que a rede de saúde do Sistema Único de Saúde (SUS) oportuniza para que essas mulheres possam decidir o momento mais conveniente de sua vida, para que ocorra um processo gestacional e, dessa forma, prevenir gestações indesejadas, assim como ressaltou-se a importância dos exames preventivos de mama e o citopatológico.

Disponibilizou-se para essa explicação um kit com os métodos contraceptivos, dentre eles o que chamou a atenção delas foi sobre a colocação do Dispositivo Intrauterino (DIU), surgindo diversas dúvidas sobre o procedimento de colocação, tempo de duração e possíveis efeitos colaterais. A ação de educação em saúde é necessária, levando em conta aspectos envolvidos na formação de valores, atitudes, hábitos e crenças populares, por profissionais, incentivando o autocuidado e a saúde, onde pode ser realizado acolhimento com escuta qualificada, valorizando suas qualidades e conhecimentos (Morin; Lüdke, 2019).

Foram realizados esclarecimentos acerca da pílula anticoncepcional, dando enfoque ao modo de uso, período fértil e ciclo menstrual. Explicações adequadas sobre o planejamento familiar são fundamentais, visto que possibilitam aos usuários liberdade para definir o melhor método contraceptivo de acordo com a sua necessidade e bem-estar (Santos et al., 2016).

Na ocasião, através das peças anatômicas do sistema reprodutor feminino, foi possível mostrar a colocação, de forma prática, de alguns dos métodos de barreira (camisinha feminina e masculina, diafragma, DIU), para que melhor compreendessem a importância do autocuidado na relação sexual, como forma de prevenção, tanto para infecções sexualmente transmissíveis, quanto para uma possível gravidez indesejada. Também se abordou acerca dos métodos hormonais (pílulas), os tipos que existem e que são fornecidos pelo SUS, dando enfoque de como tomar o anticoncepcional oral de forma correta, período fértil e o ciclo menstrual. Esclarecimentos adequados sobre o planejamento familiar são fundamentais, visto que possibilitam aos usuários liberdade para definir o melhor método contraceptivo de acordo com a sua necessidade e bem-estar (Santos et al., 2016). 
Na quarta e última etapa, observou-se que as mulheres se mostraram atentas e proativas, com muitos questionamentos, algumas mais esclarecidas se manifestavam e auxiliavam a esclarecer as dúvidas das outras, situação estimulada pelo grupo para haver troca de informações. A educação popular, como a metodologia da roda de conversa, proporciona momentos únicos de diálogo e saberes, propiciando uma comunicação dinâmica e produtiva entre os participantes, em que o entrelaçamento de saberes acontece de forma horizontal (Freire, 1983).

Teve-se o intuito de estimular a autoestima por meio de frases motivadoras e pelo sorteio de um kit com produtos de cuidados pessoais, de modo a melhorar a autoimagem, para que possam se sentir encorajadas a enfrentar da melhor forma a vida pessoal e profissional. Perante a atual sociedade, o empoderamento feminino é um argumento insuficiente para uma transformação e aceitação social, contudo, é uma etapa primordial. O contexto feminino vem se fazendo relevante neste processo de evolução, em busca de mudanças significativas para a construção de uma coletividade mais humanizada e igualitária (Alves; Oliveira, 2020).

A educação na saúde, desenvolvida por meio de ações educativas, auxilia na construção social, com a intenção de proporcionar um atendimento dialógico e igualitário, que traga satisfação ao usuário, em um processo que auxilia os indivíduos a adquirir e compreender atitudes e conhecimentos de uma determinada área (Silva; Cândido, 2018). O acolhimento realizado por meio da consulta de enfermagem é salutar, na medida em que a comunicação favorece um vínculo e confiança, proporcionando saúde, independência e responsabilidade na promoção da saúde e melhor qualidade de vida, através de ações de inclusão, integralidade e eficiência (Assunção et al., 2020).

Para finalizar o evento e estimular a autoestima, utilizaram-se frases motivadoras e foi realizado o sorteio de um kit com produtos de cuidados pessoais. Para o sorteio foram distribuídos entre as trabalhadoras papéis com o desenho do aparelho reprodutor feminino e somente um papel com o desenho do aparelho reprodutor masculino, o que gerou muitas risadas no momento da revelação da ganhadora. Sousa e Fernandes (2017, p. 13), em estudo publicado para refletir sobre a relação entre o biopoder, o riso e os corpos, destacam que as "práticas que envolvem o riso estão ligadas a saberes científicos, como que indicam que pessoas felizes vivem mais e melhor ou que um sorriso pode auxiliar na cura de doenças".

Essa atividade teve por finalidade agradecer, encorajar e motivar essas mulheres, que realizam um trabalho relevante para a sociedade e o meio ambiente e que, na maioria das vezes, não são reconhecidas e sofrem muito pela desigualdade, preconceito, falta de reconhecimento e pela vulnerabilidade que o cotidiano lhes impõe. Então, implementar ações em saúde, através de metodologias lúdicas, que estimulam e promovem o autocuidado e a autoestima, fez a vida dessas trabalhadoras, no aspecto pessoal e profissional, e das acadêmicas de enfermagem e da docente, ter um momento diferenciado de alegria, descontração e aprendizado.

\section{Conclusão}

Constatou-se no presente artigo uma jornada dupla na vida das mulheres catadoras da cooperativa de reciclagem, entrelaçando o trabalho com as atividades domésticas e cotidianas, representando uma minoria diante do número total de trabalhadores na referida instituição. Destaca-se que a maioria das mulheres são jovens, na média de 20 a 30 anos, onde se encontram inseridas pela necessidade e baixa renda. Diante disso, os cuidados pessoais podem ser deixados de lado pela cansativa rotina, não tendo tempo para questões de saúde e sexualidade, em função da sua profissão e por serem marginalizadas, o que prejudica o autocuidado e consequentemente a sua autoimagem e qualidade de vida.

Em função da busca trabalhista pela necessidade de uma renda básica, elas são muitas vezes responsáveis pelo sustento da família, deixando de lado, em alguns casos, os estudos formais, junto com a autoestima, limitando o aprendizado e o conhecimento, destacando-se assim o papel da enfermagem, diante da oportunidade de atuar de forma educativa junto a grupos 
singulares, voltado a mulheres em situação de vulnerabilidade. Ressalta-se assim a importância de uma maior valorização dessa classe de trabalhadoras, a necessidade de condições seguras e uma maior inclusão na sociedade.

Cabe salientar, ainda, a escassez de estudos acerca desta temática, e também de ações educativas com essa classe de trabalhadores, que desempenham um papel tão importante para a sociedade. Ressalta-se a necessária continuidade de estudos com catadores, que possibilitem averiguar por meio de análise situacional as fragilidades expressas nos diferentes locais em que estes trabalhadores desempenham suas atividades laborais, permitindo desta forma que estes estudos estejam focados nas necessidades elencadas pelos próprios envolvidos, para que a qualidade de vida e saúde possa ser melhorada. Para os enfermeiros em formação, as ações educativas com esta classe de trabalhadores foram primorosas para o despertar de um olhar mais abrangente da sociedade e das diversas classes sociais, compreendendo ainda que é possível, com a atuação profissional, buscar um cuidado humanizado e igualitário.

\section{Referências}

Alves, S. M. C., \& Oliveira, G. B. de. (2020). As Contribuições de Paulo Freire para o empoderamento feminino no campo. Research, Society and Development. $9(6), 1-13$.

Assunção, M. R. S., et al. (2020). A sexualidade feminina na consulta de enfermagem: potencialidades e limites. Revista de Enfermagem da UFSM. 10(1), 118.

Cavalcante, B. L. de L., \& Lima, U. T. S. de. (2012). Relato de experiência de uma estudante de Enfermagem em um consultório especializado em tratamento de feridas. J Nurs Health. 1(2), 94-103.

Coelho, A. P. F., et al. (2018). Trabalho feminino e saúde na voz de catadoras de materiais recicláveis. Texto \& Contexto - Enfermagem. 27(1), 1-10.

Coelho, A. P. F., et al. (2016). Mulheres catadoras de materiais recicláveis: condições de vida, trabalho e saúde. Revista Gaúcha Enfermagem. 37(3).

Costa, A. M. S. da., et al. (2020). Educação em saúde em uma escola infantil do interior do Amazonas: relato de experiência. Revista de Divulgação Científica Sena Aires. 1(9), 125-132.

Freire, P. (1983). Pedagogia do oprimido.

Gil, A. C. (2008). Como elaborar projetos de pesquisa.

Lemos, R. M. R., \& Padilha, T. A. F. (2018). Simulações e aprendizagens baseadas em problemas: uma experiência de uso de metodologias ativas em um curso técnico de enfermagem. Biblioteca Digital da Univates.

Loiloa, R. F. (2017). Análise discursiva da autoimagem corporal de mulheres em diferentes idades. Espelho, espelho meu!. Revista Tecer. 10(18), 26-38.

Ludke, M., \& Andre, M. E. D. A. (2013). Pesquisas em educação: uma abordagem qualitativa: E.P.U.

Morin, V. L., \& Lüdke, E. (2019). Uma comparação do conhecimento estudantil sobre saúde da mulher entre estudantes de escolas públicas da zona urbana e rural. Revista Vivências. 15(28), 50-67.

Moura, R., \& Sopko, C. (2018). Desigualdade social e de gênero: a inserção da mulher no trabalho e a dupla jornada frente ao processo de catadores no brasil. Caderno Espaço Feminino. 1(31), 228-242.

Nascimento, A. G., \& Cabral, C. G. (2017). Relações de gênero e sustentabilidade urbana: mulheres na reciclagem de materiais. Seminário Internacional Fazendo Gênero 11 \& 13th Women's Worlds Congress (Anais Eletrônicos).

Nascimento, A. G., \& Cabral, C. G. (2019). Catadoras de materiais recicláveis em natal: gênero, meio ambiente e divisão sexual do trabalho. Revista Gênero. 20(1), 18-33.

Proni, M. W., \& Gomes, D. C. (2015). Precariedade ocupacional: uma questão de gênero e raça. Estudos Avançados. 29(85), 137-151.

Rodrigues, C. F. do C., et al. (2020). Promoção de saúde para mulheres em território de vulnerabilidade social: comunidade a Saroba. Research, Society and Development. 9(10), 1-17.

Santos, R. B. dos., et al. (2016). Processo de readequação de um planejamento familiar: construção de autonomia feminina em uma unidade básica de saúde no Ceará. Revista Eletrônica de Comunicação, Informação e Inovação em Saúde. 10(3), 1-10.

Saur, A. M., \& Pasian, S. R., \& Loureiro, S. R. (2010). Desenho da figura humana e a avaliação da imagem corporal. Psicologia em Estudo. 15 (3), $497-507$.

Silva, L. V. da., et al. (2017). As metodologias ativas e atividades lúdicas na educação básica: da formação docente para a prática pedagógica no Pibidmatemática. Anais do Seminário Científico do Unifacig. 2, 1-5.

Silva, V. G. da., \& Cândido, A. da S. C. (2018). A Formação do Enfermeiro para a Realização da Educação Continuada. Revista Multidisciplinar e de Psicologia. 40(14), 847-858. 
Research, Society and Development, v. 10, n. 6, e40210615798, 2021

(CC BY 4.0) | ISSN 2525-3409 | DOI: http://dx.doi.org/10.33448/rsd-v10i6.15798

Sousa, W. K. M. V., \& Fernandes, E. M. da F. (2017). O riso e o corpo: reflexões acerca do riso e sua relação com o biopoder. Revista de Letras. 18(23), 36-54.

Thiollent, M. (2009). Metodologia de Pesquisa-ação. 14, 1-132.

Winters, J. R. da F. et al., (2018). O empoderamento das mulheres em vulnerabilidade social. Revista de Enfermagem. 4(18). 